\title{
A Portable Sisal Decorticator for Kenyan Farmers
}

\author{
Benjamin J. Snyder \\ Mechanical Engineering \\ Penn State University \\ University Park, PA \\ bjs308@psu.edu
}

\author{
Joe Bussard \\ Mechanical Engineering \\ Penn State University \\ University Park, PA \\ jab567@psu.edu
}

\author{
Jim Dolak \\ Mechanical Engineering \\ Penn State University \\ University Park, PA \\ jimd419@psu.edu
}

\author{
Tim Weiser \\ Mechanical Engineering \\ Penn State University \\ University Park, PA \\ tvw109@psu.edu
}

Abstract - This project analyzed and redesigned the various components of a previously designed sisal decorticator prototype. The sisal plant is easily grown in the arid regions of Kenya and its fiber has widespread industrial and consumer applications. Competition from Brazilian and Chinese sisal growers has made it difficult for small-scale Kenyan sisal farmers to yield a profit. Decorticator machines strip the usable fiber from the sisal leaves. A strong market exists in Kenya and beyond for an affordable and capable decortication device. Based on interaction with University of Nairobi students and faculty, design parameters were assessed and adapted to create a working prototype to meet these needs. Throughout the design process, affordability, energy consumption, transportability, reliability, on-site material and assembly constraints were taken into account. The designs chosen accomplished the project requirements by minimizing cost through material selection and ease of manufacture, and provided adjustable parameters in order to facilitate decortication quality testing. A vertical feed, small diameter decorticator with steel blades transportable via a steel frame with two wheels was determined to be the optimal solution. Testing with actual sisal and variable components enabled quality to be assessed as well as ensured that the designed prototype operated correctly and safely.

Index Terms - decorticator, Kenya, fiber, sisal

\section{INTRODUCTION}

Sisal fiber is widely used in applications ranging from rope to carpeting. Prior to 1941, Indonesia was a major exporter of sisal but its industry has since declined to virtually nothing. In the 1960s, East Africa, comprising Kenya, Tanzania and Mozambique, was the leading sisal growing region, accounting for over half of the World's sisal supply, though the region was rivaled by Brazil which was then the world's second largest producer. Those were the heydays of the East African sisal industry.

The East African sisal industry began in a modest way and was developed by individuals with limited capital. The industry took the form of relatively small plantations, the majority having only one type of decorticator. In the years between the 1960s and today, the industry changed drastically. First, the introduction of synthetic fibers, which first made significant in-roads into the traditional sisal market in the mid-sixties, led to sharp drops in the demand for sisal and in sisal prices ${ }^{1}$. As a result, many of the sisal plantations that formerly thrived in Kenya are now defunct. Secondly, the nationalization of agriculture in Tanzania, as a part of the Ujamaa ${ }^{2}$ policies, led to a drop in agricultural productivity, that of sisal included. Today, Brazil and China dominate the sisal production markets utilizing large-scale farming and processing 
techniques. Large-scale sisal farming is currently cost-prohibitive to lower-income farmers ${ }^{3}$ in Kenya. The small scale, individualistic nature of sisal production in East African has survived to the present, especially in Kenya.

The mechanical engineering department at the University of Nairobi and others have been involved for the past few years in designing and testing a decorticator to meet the needs of Kenyan farmers ${ }^{4,5}$. Low cost, portability, ergonomic considerations, safety, efficiency and high quality are all issues of concern for the individual Kenyan sisal farmer. Design calculations were discussed with the collaborating faculty at the University of Nairobi ${ }^{5}$. The presence of such a decorticator could potentially strengthen the volume of sisal exported from Kenya, in turn, benefiting the economy.

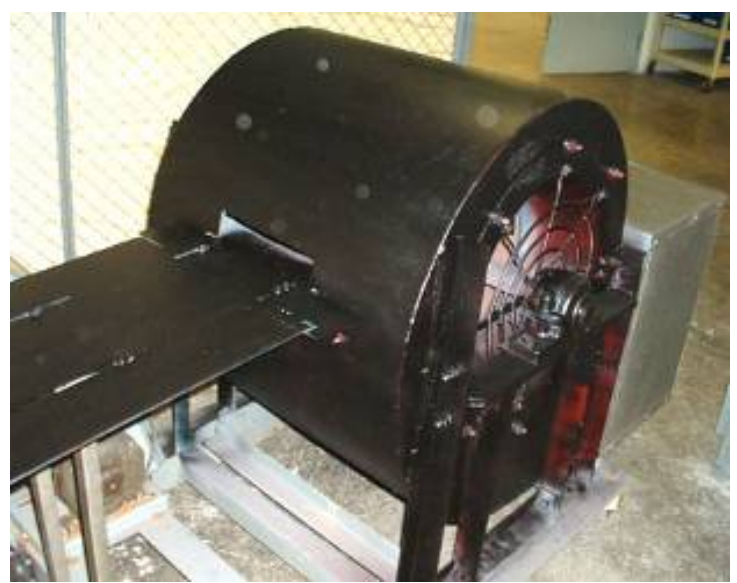

FIGURE 1

\section{Current Operational Practice}

Traditional decortication occurs as follows:

The operator manually inserts the leaf into the machine, normally butt-end first, and feeds the leaf into the machine until about half the leaf has been decorticated. The leaf is then pulled out of the machine. The operator grips the already decorticated end of the leaf and inserts the tip-end of the leaf into the machine to be decorticated. In this way, the operator manages to get the whole leaf decorticated $^{6}$. The initial prototype developed for testing is shown in Figure 1.

\section{PROTOTYPE SISAL DECORTICATOR}

\section{Decorticator Specifications}

The main purpose of this project is to analyze and modify the existing decorticator prototype to meet the needs of the Kenyan farmers (seen harvesting sisal leaves in Figure 2). In order to be financially practical for Kenyan farmers, the price should be below \$2,700 USD, though further price reduction would be beneficial. The machine must be transportable and allow sufficient yields such that Kenyan sisal farmers will be better able to compete in the world sisal fiber market. Performance goals are $140 \mathrm{~kg}$ of fiber per day.

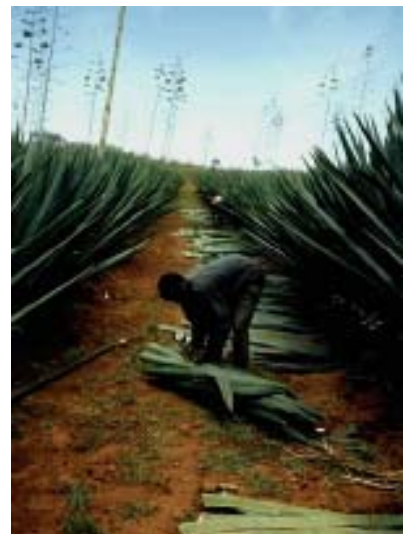

FIGURE 2

FARMER HARVESTING SISAL LEAVES

\section{Project OBjectives}

The goal of this project was to dissect an existing sisal decorticator and redesign the device to optimize performance and minimize costs. The prototype was to be designed such that it could be manufactured in Kenya using available materials and powered by existing energy sources. 


\section{CONCEPT DESIGN AND DESIGN SELECTION}

The redesigned prototype was to be tested for performance, safety and efficiency. Material selection, weight, transportability and noise were among the variables to be considered in the design process. In maintaining compliance with the Occupation Safety and Health Association (OSHA), reduction of noise levels was also an objective.

The team developed a number of alternatives for each major component of the decorticator. The major components included: cylinder/blade design, motor drive system, feed tray design, safety, mobility, and cylinder casing.

Each component was evaluated using a separate Screening Matrix. Three alternatives were considered for each component. The reference was the previous team's decorticator prototype (see Figure 1). The choices were narrowed from four to two using the screening matrix. These two alternatives were then compared in a Scoring Matrix. The matrices are included in the Appendix in Tables 1-12.

\section{Screening Metric}

The selection criteria for the Screening and Scoring Matrices were chosen with respect to the objectives for the final prototype design. The criteria used were: cost, performance, portability, weight, manufacturability, durability, safety, and ease of use. In the Screening Matrix, each alternative was assigned a ' + ' if the alternative was an improvement over the reference, a '-' if the alternative was not an improvement, and a ' 0 ' if the alternative provided no change from the reference. After repeating this for each of the eight selection criteria, the +'s, -'s, and 0's were summed to provide a net total for each of the components. The alternatives with the highest net score were chosen to be evaluated in an accompanying scoring matrix.

\section{Scoring Matrix}

The Scoring Matrix contained the same selection criteria as the screening matrix, but with each of the criterion assigned a percentage based on their relative importance for the final design. The percentages, when added up, totaling one-hundred percent. Each alternative design was rated from 1-3; with a ' 3 ' being the closest to ideal for that parameter. That rating was then multiplied by the criterion's percentage to come up with the weighted score. After each of the selection criterions were rated and weighted for both alternatives, the weighted scores were added up to give a total score for each alternative. The alternative design with the highest total score was chosen to be implemented in our final design.

\section{Evaluation Results}

The screening and scoring matrices highlighted issues with the existing prototype that were in need of refinement. These included:

- the use of metal castors for wheels,

- the overall large size of the prototype,

- the relatively hard to use feed system,

- $\quad$ and the poor safety features such as the non-functional footbrake and the lack of appropriate guarding.

- Due to its small wheels, size and weight, the existing prototype was difficult to transport, allowing room for significant improvements. 


\section{Cylinder/Blade Design}

The two alternatives considered for the cylinder/blade design were Concept A (Small Diameter with Rubber blades) and Concept B (Small Diameter with Steel blades). See Tables 1 and 2. Concept A consisted of a cylinder of approximately four inches in diameter with rubber blades attached at a to-be-determined distance apart from each other around the cylinder. Each of these rubber blades had a steel tip at the end. From cylinder to blade tip, each of the blades should be approximately three to four inches in length. Concept B consisted of the same size cylinder as Concept A (four inches), except in this design the blades should be completely made of steel. The blades would also be approximately the same length in both designs. Concept B was chosen for its durability.

\section{Motor Drive System}

The two alternatives under consideration for the motor drive system were Concept A (Timing Chain) and Concept B (Direct Connection). See Tables 3 and 4. In Concept A, a timing chain would connect the motor to the shaft to turn the cylinder. In Concept B, the motor would be directly connected by a coupling to the shaft. The main problem involved with directly coupling the shaft was the lack of speed control involved. As a result, Concept A was chosen. This was later changed to a belt drive to allow the drive system to slip without burning out the motor.

\section{Feed Tray Design}

The top three concepts considered were: Concept A (Powered Rollers), Concept B (Vertical Feed), and Concept $\mathrm{C}$ (existing horizontal feed). See Table 5 and 6. Concept $\mathrm{A}$ involved having a set of rollers powered by the motor. Concept B was a design borrowed from similar styled machines, such as a Wood Chipper (Figure 3 ), with the feed mechanism on top of the decorticator. Concept $\mathrm{C}$ incorporated the current concerns for safety and efficiency. Concept B was chosen based on safety concerns and ease of use.

\section{Safety Features}

Two new alternatives for the safety features were Concept A (Stick in Spokes) and Concept B: (Wound Spring). See Tables 7 and 8. Concept A

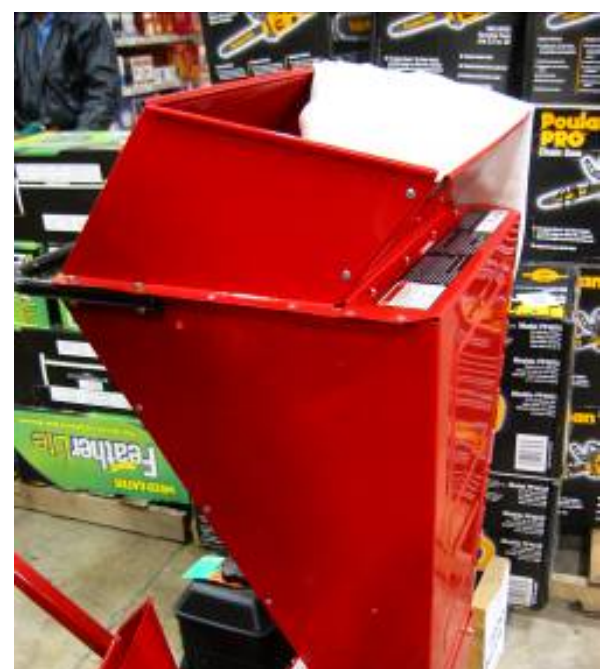

FIGURE 3

TROYBILT CHIPPER HOPPER involved having a mechanical device which would be activated in emergencies to stop the cylinder from turning. Concept B involved using a spring to absorb the rotational forces of the cylinder and bring it to a stop in an emergency. The disadvantage associated with Concept A was primarily damage to the machine itself. Concept B was chosen based on operational performance and safety issues.

\section{Mobility}

The two new alternatives for the mobility features were Concept A (Wheelbarrow) and Concept B (Rickshaw). See Tables 9 and 10. Concept A involved using one smaller, centered wheel in 
the front of the decorticator and handles similar to a wheelbarrow. This concept uses a push motion to move the decorticator. Concept B involved using two larger wheels and longer arms similar to rickshaws used in Asian cultures. This concept would use a pulling motion to move the decorticator. Concept $\mathrm{B}$ was chosen. However, when initially designing the mounting frame, it was clear that a combination of the two concepts would be a more simple and effective design. The new design will incorporate two small wheels on the wheelbarrow frame.

\section{Cylinder Housing}

Two new alternatives for the casing that houses the cylinder were Concept A (Plastic Box) and Concept B (Sheet Metal Box). See Tables 11 and 12. Concept A utilized a steel frame to create a rectangular box. The box was then covered in rectangular pieces of clear plastic to safely enclose the cylinder and blades. Using a clear material enabled the operator to view the decorticating process and observe and jams or blade failures and have more acoustical dampening from vibration than metal. Concept B employed a steel frame with sheet metal coverings instead of plastic. The metal had a high ductility and strength. Concept A, utilizing a steel frame with acrylic plastic siding was chosen.

\section{Detailed Design}

\section{Technical Specifications:}

The final design emphasized operational parameters as well as minimizing costs. The proposed design, shown in Figure 4, consisted of a vertical hopper feed coupled to a steel-reinforced acrylic sheet box as illustrated. The box contained a hollow 4" diameter aluminum cylinder on

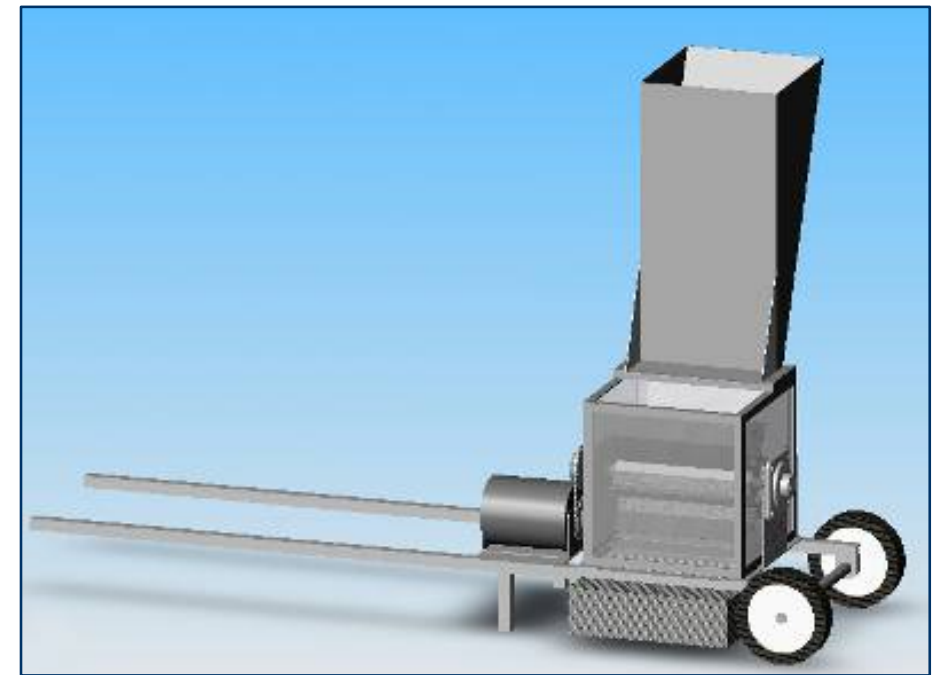

FIGURE 4

PROPOSED DECORTICATOR DESIGN which 2" stainless steel blades were mounted to steel angles. The cylinder connects via a shaft to a steel arm that was attached to the bottom of the box. Horizontal flange bearings allowed the shaft to spin freely within the configuration. Attached to one end of the shaft was a pulley which was driven using a belt attached to a 1/3$1 / 4$ horsepower electric motor. The cylinder box, bearing arms and motor were mounted to two 1" square steel tubes using steel plates for support. The steel tubes formed the frame and handles for the decorticator, and connected to a shaft at the front of the device on which 8" wheels were mounted. Landing legs allowed the decorticator to sit flat when not in transit. A collection bin (Figure 5) was attached to the side of the cylinder box to collect the decorticated sisal fiber and waste plant parts. Safety features included guarding over the chain drive and the overall feed system design. The decorticator sits approximately 4 feet high from the bottom of the 8 " wheels to the top of the feed hopper and is 
approximately 6' long. The steel frame on which the decorticator sits provided an easy mode of transportation by hand, and may also be adapted for use in towing applications.

\section{Operational Description:}

The decorticator worked as follows: The machine operator plugs in and turns on the electric motor. This was done by flipping a switch on the motor power cord. Once the machine is up to speed, the operator then took sisal leaves and placed them inside the hopper (Figure 6). The sisal was allowed to enter the cylinder box by gravity and was funneled in order to retain contact with the adjustable aluminum breast plate. The decorticator blades then contacted the leaves, stripping the fiber against the breast plate and pulled the sisal through to the collection bin. The decorticator can be shutoff using the switch or, in the case of an emergency, a kill switch that is located within the reach of the operator. The switch currently acts much like the power switch but provides a

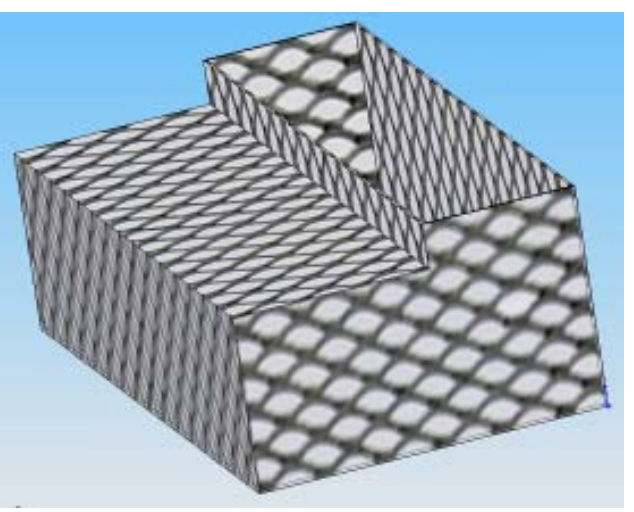

FIGURE 5

STEEL MESH FIBER COLLECTION BIN highly visible and easy to use power down mechanism. Due to the design of the feed system it is not anticipated that a brake to the cylinder will be necessary.

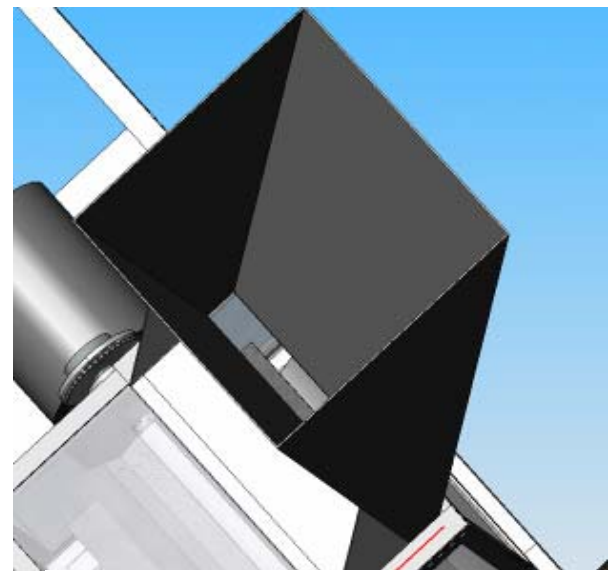

FIGURE 6

HOPPER/SISAL INPUT LOCATION

In order to prevent the possibility of operator injury while running the decorticator, the vertical feed hopper, having a small opening at the entrance to the cylinder drum as well as a large guard in its general form, ensures that the operator cannot make direct contact with the spinning blades. Additionally, guarding on the drive train system prevents contact with the pulleys and belt. Testing of the decorticator to determine if any other hazards exist as well as the amount of time it takes for the cylinder to stop following full speed operation will dictate the necessity of a braking system.

Use of acrylic for the cylinder box (Figure 7) provided acoustical dampening while presenting a cost effective alternative to metal. The material chosen for the component, manufactured by Lucite, provided strength of up to 100 times that of glass, ensuring that decorticated sisal particles did not puncture the cylinder box nor harms the operator.

Testing was conducted to ensure that the decortication process follows expectations. As a result, an additional design consideration was suggested; that is, to include a roller cylinder mounted close to the interior side of the feed hopper.

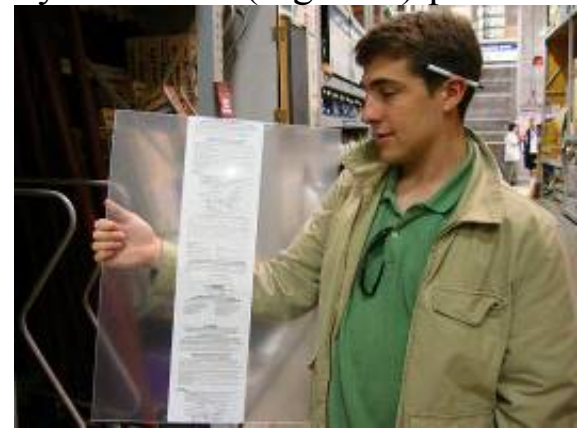

FIGURE 7

LUCITE ACRYLIC SHEETING 
The roller cylinder should be powered either by an additional belt attached in series to the pre-existing pulley on the cylinder drive shaft or by a manual hand-crank (see Figure 8 for cylinder and blade assembly). For the automatic configuration, the gearing of the roller cylinder would be such that the roller cylinder would spin at a lower angular velocity than the main decorticating cylinder, allowing a constant feed rate and preventing the sisal leaves from being pulled through the cylinder without being sufficiently decorticated. The estimated cost of implementing the powered roller feed system was $\$ 50$ while a manual system could be accomplished for approximately \$20. Testing indicated that a roller system was indeed necessary.

When sisal was fed into the original prototype, the beater roller design pulled the plant through without decorticating any of the fiber (see Figure 9). Only by holding the plant back could decortication be accomplished, adding risk of operator injury as well as lower quality decortication (the entire plant could not be fed in, lest the operator's hand let go just before the end of the plant reached the beater blades).

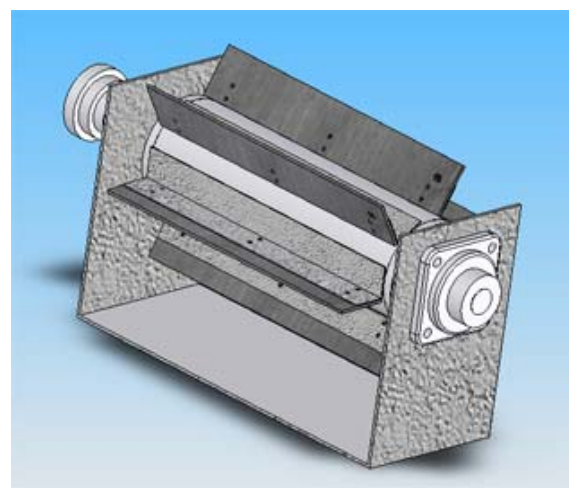

FIGURE 8

CYLINDER, BLADE, BEARING AND ARM ASSEMBLY

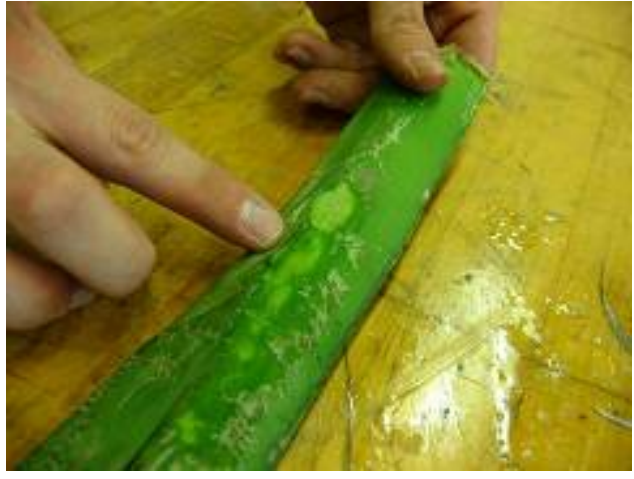

FIGURE 9

ORIGINAL PROTOTYPE

DECORTICATION - ONE PASS

\section{DESIGN IMPROVEMENTS:}

Several modifications were implemented to improve the design following construction of the prototype. Feedback from Kenyan faculty/farmers was also utilized to ensure that the design met project goals. One significant change was the placement of the feed hopper on the top of the decorticator box. The original design called for the hopper to be placed at the edge of the box, allowing the sisal to be stripped but not bent. The new design placed the hopper in the center of the box (as seen in Figure 10). In addition to bending the sisal upon reaching the beater blades, this change allowed the sisal to make contact with the breast plate and blades for a greater distance. It is estimated that this will further increase the quality of decortication.

Another change was the move from a timing chain drive system to a belt drive system. Primarily a safety precaution, belts were instituted into the design to allow slipping should the cylinder jam, rather than risk burning out the electric

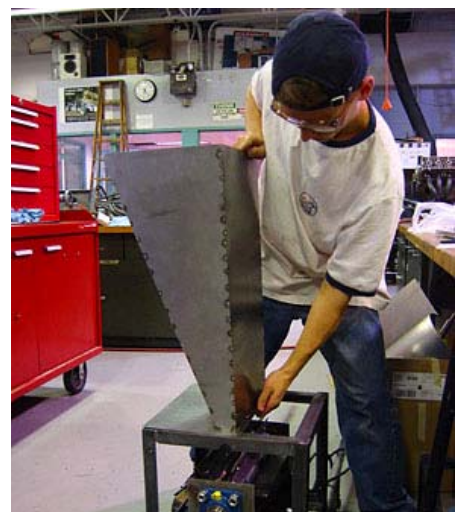

FIGURE 10

PLACEMENT THE VERTICAL FEED HOPPER ONTO THE DECORTICATOR 
motor. Additionally, the motor was moved from its place just below the rickshaw frame handles to sitting just off of the base of the machine. This change was instituted in order to fit the pulleys necessary to achieve the desired gear train ratio of approximately 1:4.7. The motor speed was measured with a tachometer and found to be approximately $1700 \mathrm{rpm}$. This would make the beater cylinder rotate at approximately $360 \mathrm{rpm}$.

A primary improvement, as previously mentioned, was the installation of a gripper roller system. This presented several design challenges which ultimately delayed completion of the prototype. Due to the high cost of the higher load flange bearings used on the main beater cylinder shaft, similar bearings were not used for the gripper shaft. The gear ratio between the main cylinder shaft and the gripper shaft was arbitrarily chosen as 1:3.83 (approximately 1:4). This enabled the gripper roller to rotate at a slower rate in order to restrain the sisal from being pulled straight through the decorticator by the beater blades. Additionally, the slow rotation (approximately 60-90 rpm) of the gripper was not estimated to need a complex bearing. Due to these factors, cost and time, a bronze sleeve bearing was used to provide shaft rotation as well as restrain lateral motion of the shaft. A pulley with three built in diameters was attached to the main cylinder shaft in order to test ratios of 1:2.9 and 1:2.3 to allow flexibility in the gripper roller speed and moreover, the feed rate.

Another significant change made as compared to the original design was the use of steel for key components rather than aluminum. The main beater cylinder was originally designed to be made of aluminum for lightweight operation. This was replaced with steel materials (see Figure 11). Additionally, using steel throughout the design facilitated assembly greatly by allowing welds to be used for more connections. Welding was favored over using strictly bolts due to assembly time and the added cost of materials. The downside, however, was that components, once welded, were made permanent. This may impair future design teams that continue work on the project by limiting access to the components. Key welded parts were the main beater cylinder and shaft, the

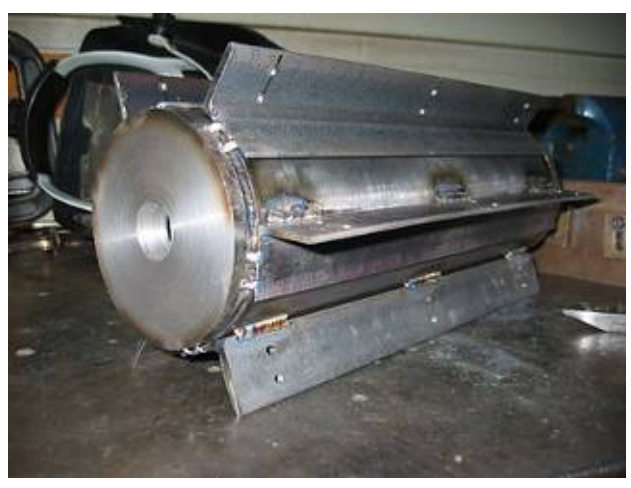

FIGURE 11

STEEL BEATER CYLINDER WITH BLADE MOUNTS rickshaw frame, the decorticator box and the hopper. As

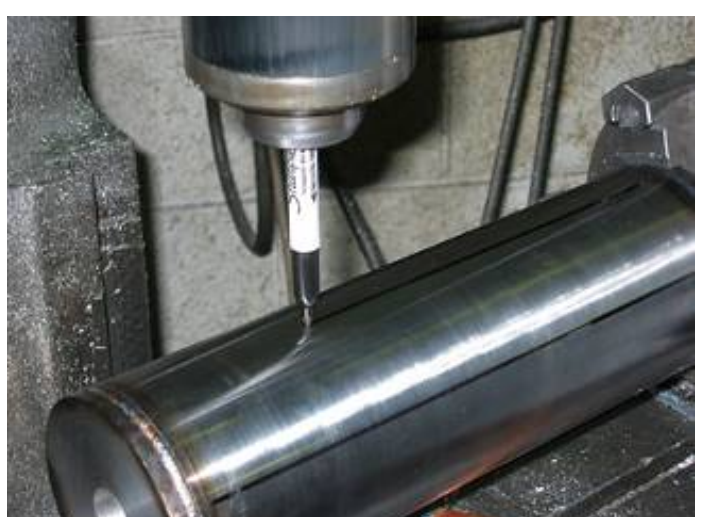

FIGURE 12

MARKING THE BEATER CYLINDER previously designed, the cylinder blades were made removable by using 3 \#10 bolts, 6 lock washers and 6 nuts per blade.

The manufacturing techniques used covered a wide spectrum of processes, from welding and milling to lathe-work and water-jet cutting. Much of the frame construction utilized standard cutting and welding for assembly, as did the decorticator box. The beater cylinder (Figure 12) proved to be one of the more complex operations, requiring lathing to create the two end caps, cutting and drilling to create the blade mounts and blades and welding and bolting to put the assembly together. The feed hopper, decorticator box and cylinder frame arms 
were welded to the rickshaw frame, creating a very solid and strong platform for the rotating beater cylinder, gripper cylinder and motor. Parts that were bolted in place include the breast plate, beater cylinder bearings, motor, wheels and Lucite side panels. Fabrication of the prototype was done over a five week period, with significant time dedicated to each day (see Figure 13 and Figure 14).

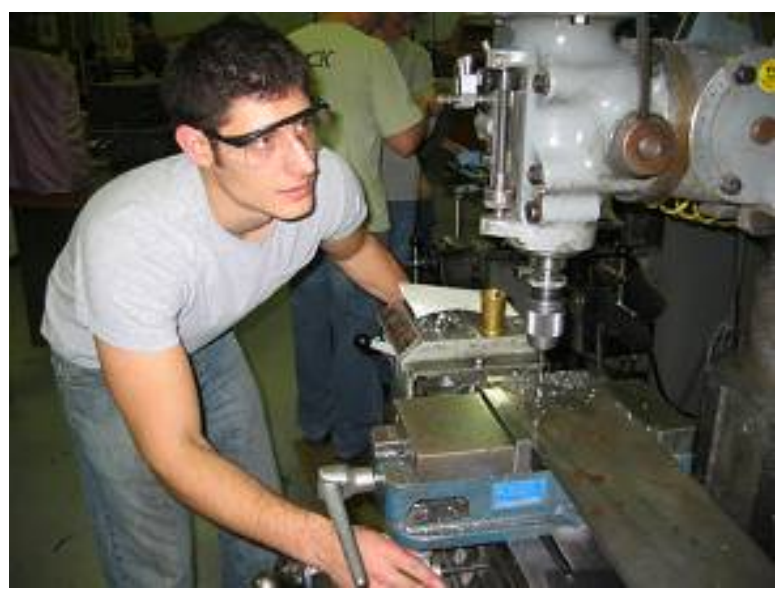

FIGURE 13

DRILLING HOLES IN CYLINDER FRAME ARMS

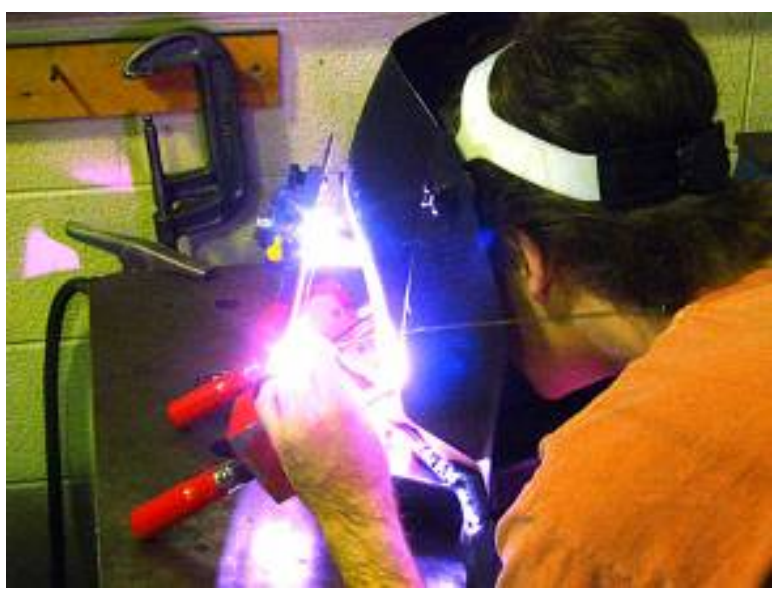

FIGURE 14

WELDING CYLINDER FRAME ARMS

Updated SolidWorks drawings were created to reflect the design changes, resulting in the conceptual prototype as shown in Figure 15.

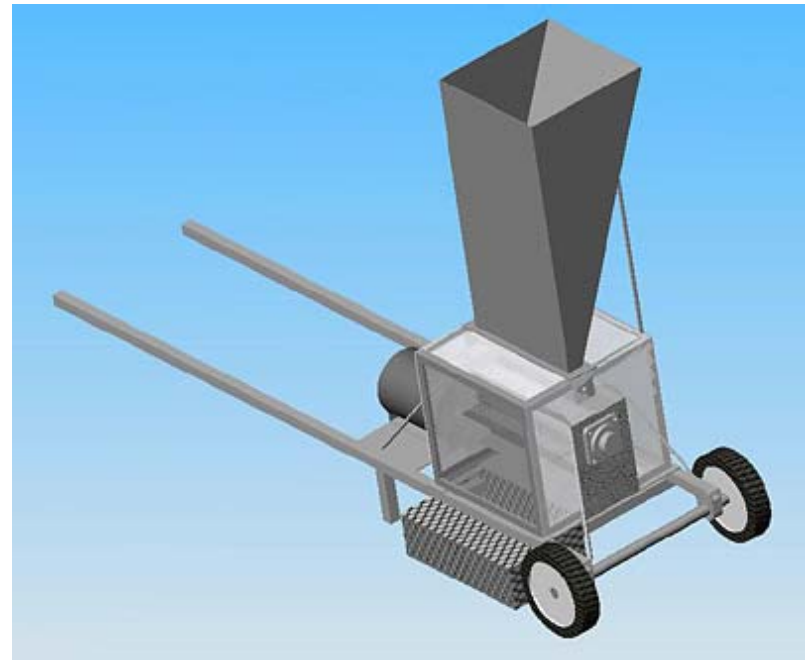

FIGURE 15

UPDATED DECORTICATOR DRAWING 


\section{ThEORETICAL ANALYSIS}

In addition to cost saving decisions and mobility concerns, the performance of the decorticator prototype weighed heavily in the design considerations. The following equations allowing quantification of the performance were provided by faculty collaborators in Nairobi. Decortication quality will be evaluated based on the equation:

$$
p=(2 \pi v) /(\omega n)
$$

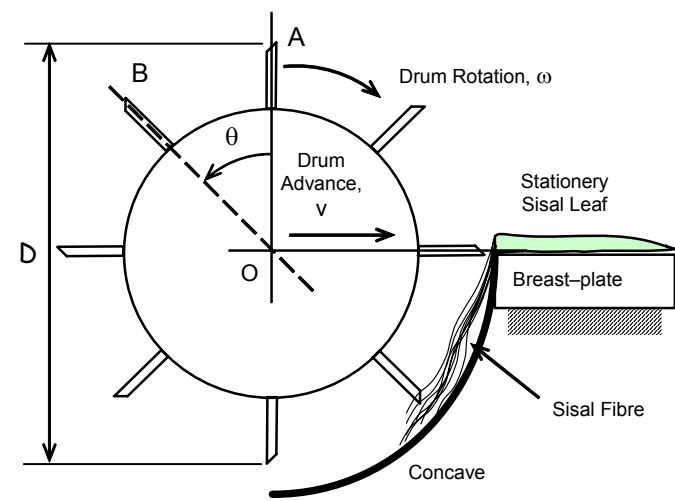

FIGURE 16

KINETIC MODEL OF THE RASPADOR

where $p$ is the pitch and represents the quantity (length) of the tissue extracted from the sisal leaves. $v$ refers to the linear feed rate of the sisal leaves to the decorticator (Figure 16) ${ }^{7}$. In our design, $v$ is controlled by gravity and the rotation of the cylinder blades through the vertical feed, or by the feed-roller system, depending on testing evaluations. $\omega$ refers to the angular velocity of the cylinder drum assembly. $n$ represents the number of blades attached to the cylinder.

Optimal values for the pitch are currently unknown and must be determined through testing. As a result, as the relationships between the parameters are not accurately known (i.e., whether or not it is optimal to have a high rotation speed, etc.), the parameters remain flexible to our design. The decision to include 6 blades $(n=6)$ was made in order to reduce costs (as opposed to using 8 blades as shown in Figure 16). Additionally, the rotational speed and feed rate can be modified by gear ratio choice (assuming a single speed electric motor).

The power required for decortication may be determined using the equation:

$$
\mathrm{W}=\left(\omega_{\mathrm{m}} G D F_{e}\right) / 2
$$

where $\omega_{m}$ is the rotational speed of the motor, $G$ is the gear ratio $\left(\omega / \omega_{m}\right)$, D is the diameter of the cylinder with blades attached (in our prototype, $\mathrm{D}=10 \mathrm{in}$.) and $F_{e}$ is the decorticator resistance (Figure 17$)^{8} . \omega_{\mathrm{m}}$ is given by the motor properties and will be determined through testing using a dynamometer. The resistance force "is probably a function of time $t$, beater drum rotational speed $\omega$, and the clearance, $c$ between the beater blades and the breastplate. The decorticator resistance can be expressed as:

$$
F=f(t, \omega, c)
$$




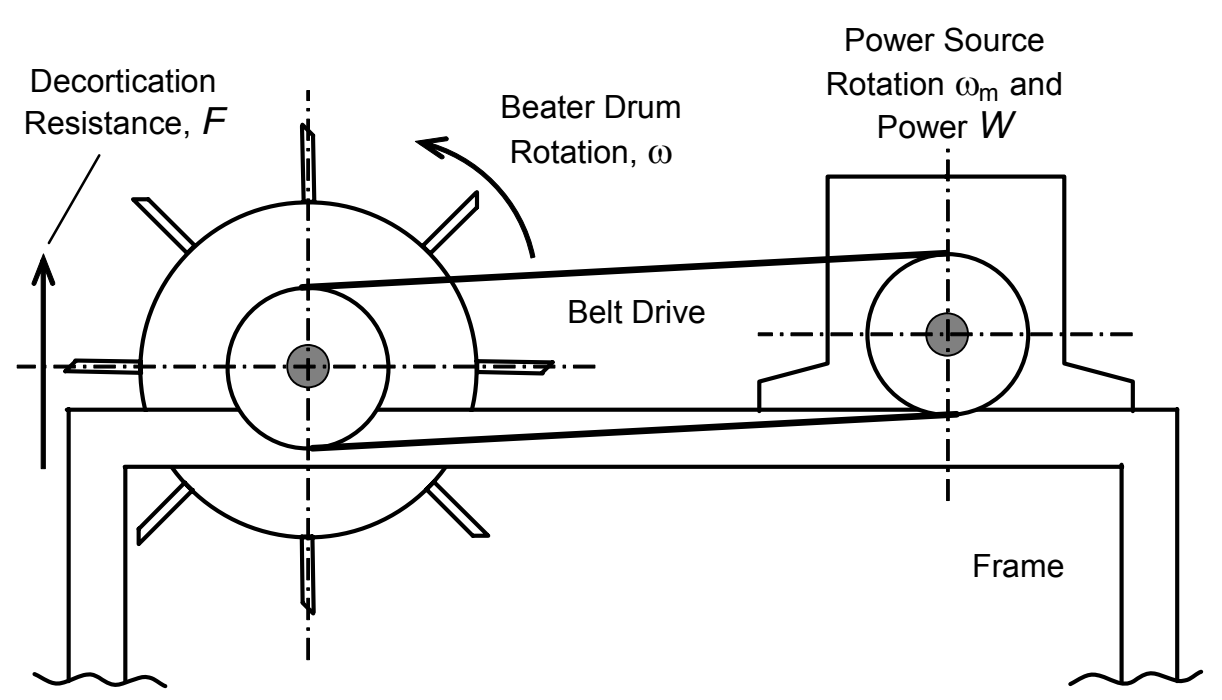

FIGURE 17

KINEMATIC MODEL OF THE DECORTICATOR DRIVE TRAIN

In the previous equation for force, it is shown that the resistance can be affected by adjusting the rotational speed of the motor and the clearance. The effects of these variations on decortication quality must be determined through testing.

Other aspects of the design that may require stress and force calculations include shear stress analysis for connecting joints, bending stresses considerations and torque. Shear stresses will be introduced in using a key to secure the main aluminum cylinder/disc assembly to the steel shaft. Key failure follows approximately the equation:

$$
\tau_{x y}=F / A_{\text {shear }}
$$

where the applied force will be calculated as the torque of the shaft divided by the shaft radius ( 1 in.) and $A_{\text {shear }}$ is the face area of the key (to be determined by key selection). The shear stress will be compared to the published shear yield strength of the material in order to ensure key failure does not occur. Shear stresses will also play a role in determining the size and type of bolts to use to attach components together, including connections between the metal frame and acrylic sides and between the bearings and the cylinder arm assembly. As the primary considerations in constructing the prototype decorticator are cost and the act of decorticating itself is not a high stress, high force operation, these calculations are not expected to prove critical to the design process. Steel and aluminum are the primary materials used in the design and have sufficient material strengths to withstand the estimated loadings. However, the calculations will be useful in evaluating the durability and reliability of the machine throughout its operative life.

\section{Manufacturing Process Plan}

The manufacturing process plan for the sisal decorticator consisted of many different operations in order to complete an affordable working product. Please note that changes were initiated during the fabrication process and are referenced in the previous Design Improvements section. 
The instructions contained herein describe the original design specification manufacturing plan. Aside from the changes aforementioned, the manufacturing plan is the same.

The first operation was to create the inner cylinder which was to do the actual decorticating of the sisal. This was accomplished by machining bores at the ends of the aluminum cylinder to enable aluminum discs which were inserted at the ends. Next, a 1" diameter shaft was fitted with the aluminum discs by a parallel keyway. The parallel keyway was machined into both components. Due to time constraints, the shaft in the current design was welded to the discs instead of connection with the keyway. The six stainless steel blade mounts were then bolted to the aluminum cylinder to ensure a safe bond between the two. After completion $1 / 8$ " thick stainless steel blades, cut to 3"x12", were screwed to the mounts for easy removal and maintenance (Figure 18). The cylinder arm assembly was then created by cutting a $1 / 8$ "x 36"x 6" steel plate in order to create two support arms for the shaft of the cylinder and a plate for welding the two arms 15" apart. The arms were then drilled to create attachment holes for the flange bearings which were bolted to the plate.

A frame was then created in which the inner cylinder were inserted. This consisted of cutting $3 / 4$ " $\mathrm{x}$ $3 / 4$ "x6' ASTM A36 steel that was $1 / 8$ " thick at 90 degrees into twelve pieces about 14" long each. These were then welded together to create a cubic frame for the cylinder. Next, three panels of $1 / 8$ " thick acrylic plastic were cut into approximately 13.75 "x13.75" sheets. Two of the sheets had a hole drilled to allow the 1 " diameter shaft to slip through so the gear could be inserted outside of the machine. These sheets also had a hole to fit the gripper roller

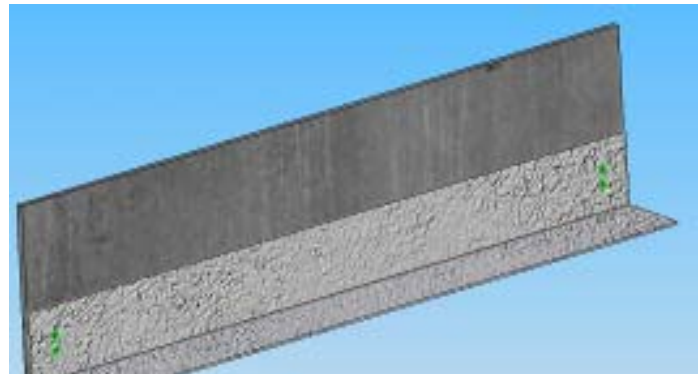

FIGURE 18

STAINLESS STEEL BLADE ASSEMBLY and were cut in halves to facilitate installation and removal. 1/16"x13.75"x13.75" sheet metal was used to line the bottom of the frame to add rigid support. A breastplate made from aluminum sheet metal extended from the top of the frame where the hopper started to the very bottom of the frame flush with the sheet metal already lining the frame. This breastplate was screwed into the frame containing the inner cylinder at the top and attached to an adjustable screw or spring at the bottom of the machine in order to allow variation of the clearance. The top of the machine consisted of a sheet metal hopper that was 24 " tall and was $1 / 32$ " thick. This was created by cutting the sheet metal to the desired dimensions and then by either riveting or welding the components together. The hopper needed supports so it could rest on the frame. This was done by welding or bolting a rectangular stock together so the hopper could rest on the frame. It is recommended that the hopper is mounted when all the other components for the entire design have been successfully completed and mounted to allow easier assembly of the other components. 
The rickshaw was then created and consisted of two 6'x 1"x 1" square steel tubes that were

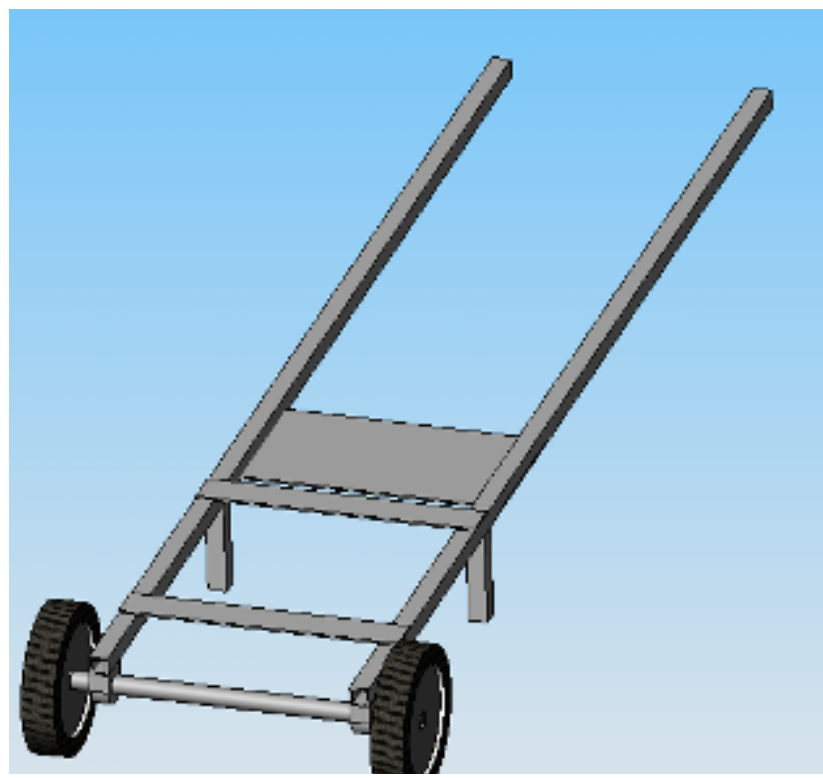

FIGURE 19

RICKSHAW ASSEMBLY $1 / 8$ " thick. This was used to mount the frame and the supports for the wheels to allow easy mobility of the decorticator (Figure 19). In order to keep the decorticator balanced on the ground two support legs made of leftover steel stock material were welded to the two tubes. The supports for the axle can also be welded at the ends of each tube to allow a shaft to slip through. Next, a plate was welded or bolted to the frame for the motor to rest on and also to support and restrain the tubes 15" apart from another. Following this the axle was slipped through and welded to the supports with 8 " diameter wheels with built-in bearings secured at the ends.

The inner cylinder, frame/hopper for the inner cylinder, and the rickshaw was then brought together to create the decorticator. This was done by welding the plate for the arms to the frame of the rickshaw and then by bolting or welding the frame to that base plate. The arms with the attached bearings were then welded to the same base plate and the shaft of inner cylinder with the blades slipped through. At the same time, the acrylic plastic was carefully attached to each side of the cylinder. After the shaft had been inserted, set screws were used to secure the shaft from sliding out from both sides. The drive train pulley was inserted at the end of the shaft to allow a belt to be attached around it. This belt was connected to the 1/3-1/4 horsepower motor via another pulley (Figure 20). The assembly of the hopper and the frame was bolted or welded together as well as the waste bin that was non-permanently attached in order to collect and remove decorticated sisal fiber. Finally the motor was place and bolted on a plate that was welded to the 6' long tubes with a respectable distance away to allow sufficient slack in the belt. The

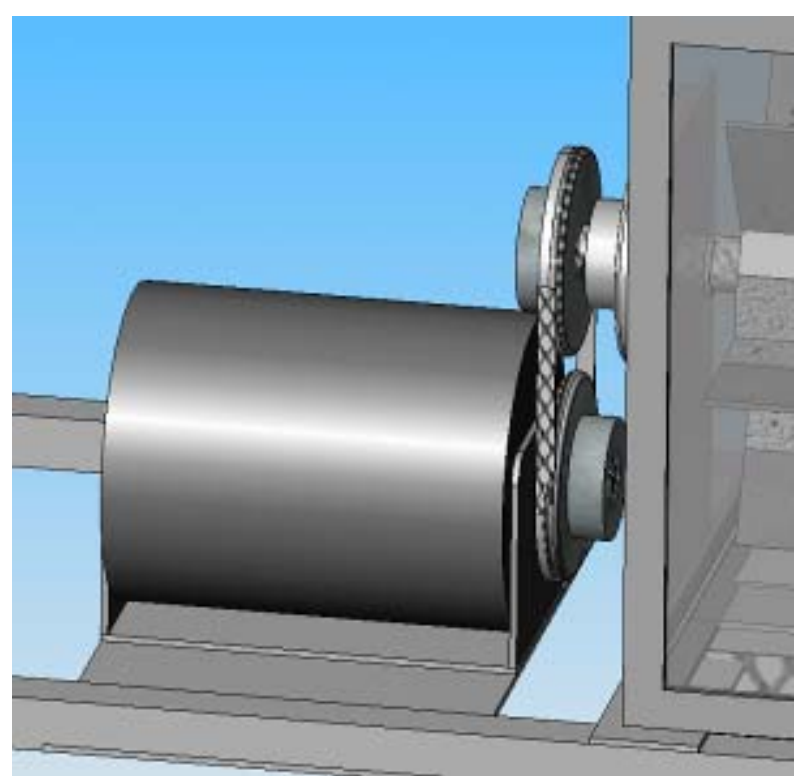

FIGURE 20

MOTOR, DRIVE TRAIN ASSEMBLY main motor belt was tensioned by making the motor height variable.

\section{Design Performance ReView}

The new design was assembled and tested in order to determine the speed and effectiveness of sisal decortication as shown in Figure 21. To enhance performance of the machine, the decorticated leaves were studied and adjustments made until the processed leaves have the 
desired characteristics. Ideally, the green outer skin should be fully removed exposing all of the usable fibers along the entire length of the leaf. Each component of the prototype was analyzed individually as the entire system was operating.

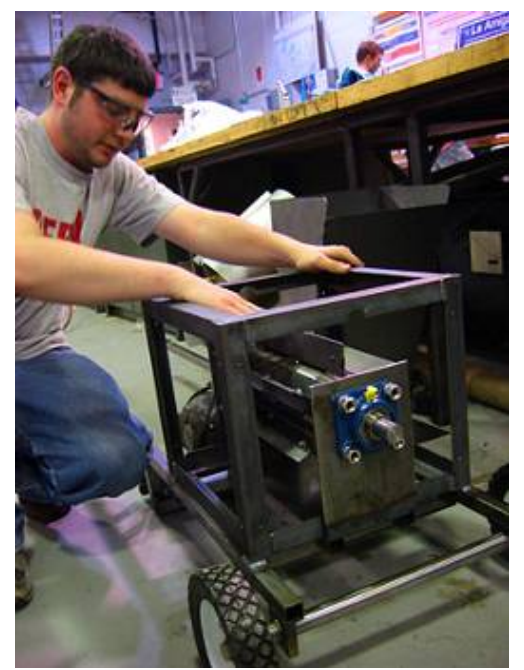

FIGURE 21

DEMONSTRATING THE

DECORTICATOR ASSEMBLY

When evaluating the components directly associated with decortication, the main variables of interest are the rotational speed, feed rate, and clearance between the breast plate and blades tips. The speed affected how many times the blades contacted the sisal as it was fed through the machine. The speed of the cylinder was calculated after determining the speed of the motor. Speed is a major component of both the pitch parameter and the power parameter. Changing the speed to accommodate one parameter affects the other. Speed was also dependent on the gearing used in the drive train. Varying the speed required purchasing and installing new gears. Due to these inherent drawbacks in varying the rotational velocity of the cylinder, the speed was kept constant for experimental testing.

The desired value of pitch was not precisely determined. Because of this, initial estimates of appropriate pitch must be evaluated using trial and error. Rotational speed and feed rate both affect pitch. Both variables are able to be adjusted by using

different sized pulleys.

The clearance was also adjusted so that the blades strip the skin cleanly while not cutting into the fibers far enough to damage them. This was accomplished by moving the breastplate rather than lengthening the blades. Clearance was one of the only components of the power equation that was easily variable. For that reason, determining the ideal power through experimental testing was dependent on clearance.

The drive system was tested for reliability in startups and shutdowns. The speeds of the pulleys were measured and compared to theoretical calculations to determine how efficiently power was being transferred through the belt drive.

Design components that were not vital to the decortication process should be tested individually. The casing provides housing for the cylinder and blades but did not directly affect decortication. The main concern for the casing is strength and vibration. Strength can be found in the material specifications. The plastic was tested for noise vibration while the machine is in operation. The performance of the mobility feature is dependent on the ability of an average person to move the decorticator without assistance. The safety component had no affect on the performance of the decorticator but it is important to the overall design. The safety features will be added late in the construction or testing phases so that other components can first be accurately tested. Stoppage devices were tested on how quickly they can bring the machine to a total stop. Safety guards were implemented to make sure no fingers or hands can enter the decorticator during operation. 


\section{Design Performance Evaluation}

The prototype currently delivers on several of the team's goals, including cost, portability, safety and manufacturability. Because the design of this prototype was based on the research and design principles by Dr. Moses Oduori, the designs were submitted to him and updated to reflect his specifications. Thus, the design closely follows the agreed upon specifications. Design changes made included the movement of the vertical feed hopper from the edge of the decorticator box to the center axis of the main beater cylinder and shortening of the blades from 3 inches to 2 inches. Shifting the hopper followed benchmarks of currently existing decortication technology while the resizing of the blades reduced the potential for bending in the blades as well as cutting down on materials and costs.

Full scale tests with actual sisal are currently pending. Based on the consistent clearance obtained with the breastplate and gripper roller as well as the well balanced main beater cylinder, it is fully expected that the tests will be successful. Clearance will be adjustable by the operator, both for the breast plate and gripper cylinder, allowing flexibility in the design. The previous prototype utilized two adjustable screws attached to springs to modify the breast plate clearance. However, during operation, the blades forced the springs down, resulting in inconsistent clearance. As a result, full decortication was not achieved. After one pass through the previous prototype, very little cortex was stripped from the plant (see Figure 9).

Only after multiple passes with manual gripping of the sisal plant was a better (though still relatively poor) decortication possible (Figure 22). The current design is expected to alleviate these problems. As previously mentioned, the gear ratio between the main beater cylinder and the gripper cylinder is also adjustable to three settings (with appropriately sized belts), allowing the automatic feed rate to be varied. Limited

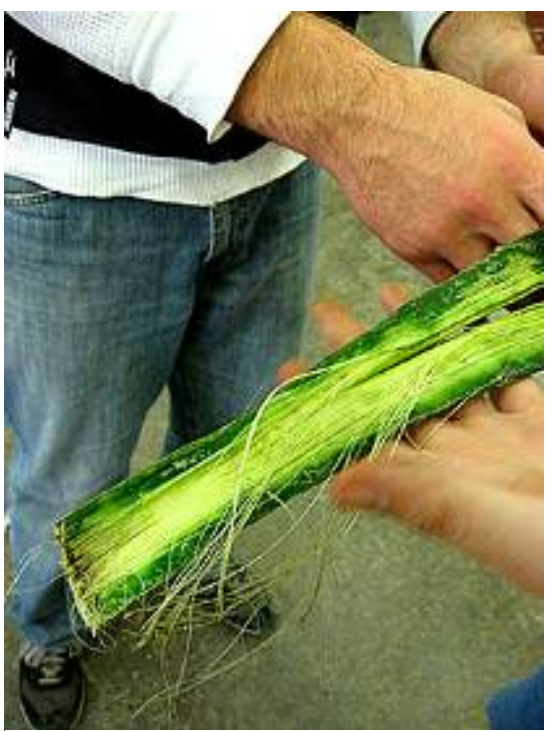

FIGURE 22

ORIGINAL PROTOTYPE DECORTICATION - THIRD PASS testing of the new prototype with existing sisal was accomplished. Initial trials yielded fully decorticated leaves obtained in a single pass through the decorticator. However, variance was observed in the quality of decortication among trials, and will require further testing to determine optimal clearance values and feed speeds.

Additionally, the weight of the prototype was greatly reduced as compared to the original prototype. While movement of the original prototype required at least two people, the current prototype can easily be maneuvered by a single operator. A significant mechanical advantage was realized by using the rickshaw/wheel barrow transportation concept while the two front wheels allow turning maneuvers (the previous design utilized three castors, making turning and general movement very difficult). The force necessary to lift the handles of the decorticator was measured as approximately $26 \mathrm{lbf}$ (see Figure 23). It was not possible to measure this parameter for the previous prototype as it had no means to lift the device. The calculated pitch of the current prototype was 0.096. Evaluation of this value is difficult to determine as an appropriate number for the pitch was not provided. However, the pitch of the current prototype provides a basis on which future testing can be done in order to establish benchmark values. Additional 
prototype strengths include robust construction due to the welded steel frame. Quieter operation was realized as well. As the cylinder does not maintain direct contact with the breast plate due to

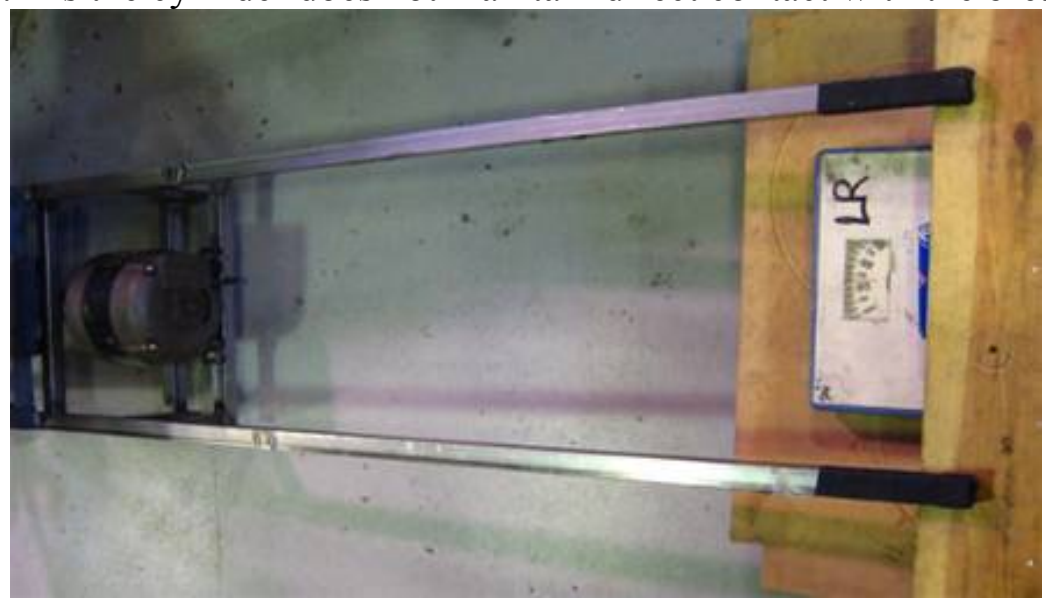

FIGURE 23

FORCE TO LIFT THE DECORTICATOR

the engineered clearance, the scraping noises present in the original prototype were absent. Further, the Lucite acrylic sheeting provided acoustic impedance as compared to resonance given by sheet metal (Figure 24). Finally, natural damping was provided through the tight fittings and connections as well as the overall weight of the prototype. Observing the new prototype in operation, this reduction in vibration and noise was clear.

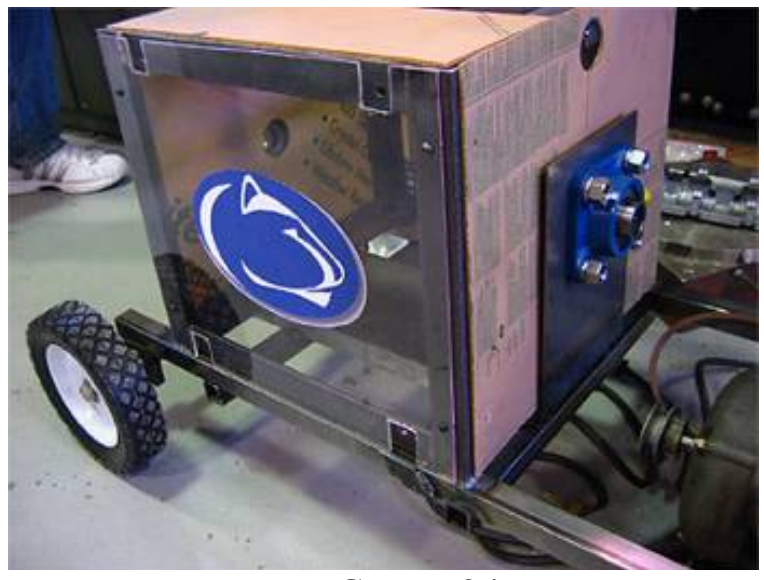

FIGURE 24

LUCITE SIDING INSTALLATION

\section{CONCLUSIONS AND RECOMMENDATIONS:}

This design was able to incorporate a variety of improvements over the existing prototype. In addition to the cutting ability of the decorticator, there were enhancements to manufacturability, weight, portability, safety, and ease of use. The design was demonstrated as having high manufacturability through simple assembly. Further, communication with Nairobi faculty confirmed the availability in Kenya of the manufacturing processes used. Some areas that could have been improved with regards to assembly were ease of dismantling certain components. 
Due to time constraints, several components, such as the beater cylinder and shaft, were welded together. In the cylinder case, a key way and cotter pins may have been adequate to restrain lateral motion of the cylinder and still allow it to be removable. The welded assembly is fixed in the decorticator.

As extensive testing was not realized due to time limits, it was recommended that future design teams assigned to this project should test the variable parameters available in the prototype, including using different blade materials and feed speed gear ratios. Additionally, it was recommended that tests concerning the safety of the Lucite panels as compared to sheet metal should be conducted. The impact strength of the Lucite was determined through literature to be $0.4-0.5 \mathrm{ft}-1 \mathrm{~b} / \mathrm{in}$. This value was obtained from a material safety data sheet available online from The Gund Company. The force of a sheared blade impacting the glass was not calculated due to time constraints. However, the force of the blade tip hitting a fixed object in its travel was calculated as approximately $27 \mathrm{lb}_{\mathrm{f}}$.

The primary successes of the design center on cost and mobility, though initial performance testing produced positive results. The rickshaw / wheelbarrow frame supported the decorticator well. Due to the complexity of the design and the large scope of the project, some elements, including the seating of the motor, had to be changed from the original design. The motor was

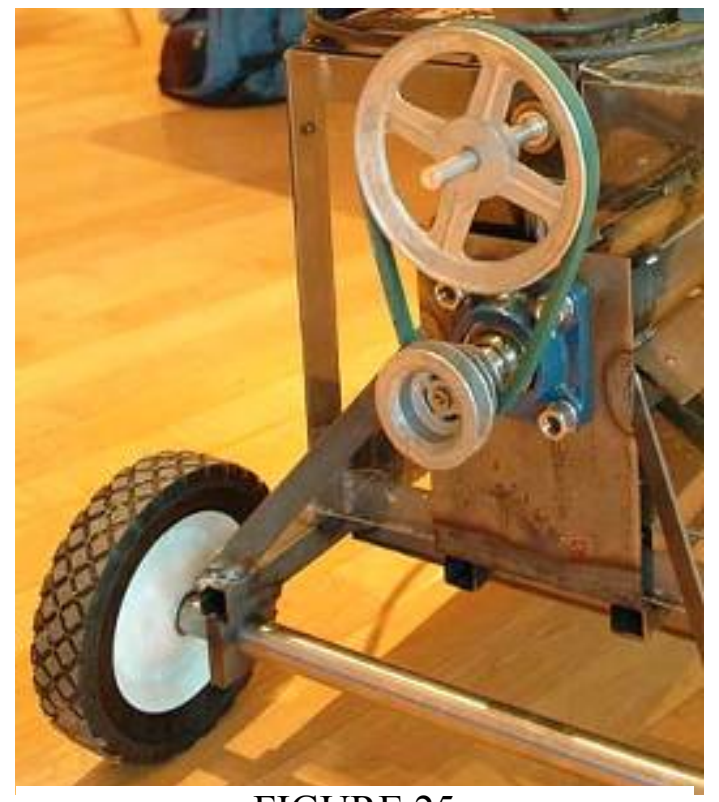

FIGURE 25

BELT DRIVE installed lower than initially planned in order to provide tensioning for the drive train system. As a result, some extra square tube steel was used that was not necessary. This added slightly to the weight of the prototype but was not deemed critical.

The elements that were tested during construction worked well and should remain in the design. The elements relating to the decorticating process including proper clearance values for the breastplate and the gripper mechanism were installed late in the design and so were not tested. The drive system itself should have had higher priority early on in the conceptual stages. Because it was installed late in the manufacturing stage, problems encountered, including the possible use idler pulleys and belt tensioning, were not adequately addressed (Figure 25). While these elements were designed to function correctly, a true assessment of the viability of these components was not completed. Thus, these areas may have had opportunities for improvement.

Despite the time constraints, a significant amount of work on completing the prototype design and fabrication was accomplished (Figures 26 and 27). The design was robust and it was expected that performance parameters would meet the goals of the project. Performance using the test sisal leaves produced full leaf decortication at a decibel level significantly less than that of the previous prototype. Additionally, the gripper roller performed as designed, alleviating the need for the operator to reach into the feed system. Vibration throughout the machine was well dampened, allowing relatively smooth operation. The overall cost of approximately $\$ 750$ (including estimates for donated parts) fell far below the $\$ 2,700$ benchmark while the prototype itself was fabricated and assembled within the $\$ 600$ design budget. The project also provided 
machining experience with catalogue ordering of parts, primarily through McMaster Carr and MSC. From the fabrication process, a greater knowledge of designing for manufacturability was attained. Future revisions to the design will include installation of safety guarding and a kill switch as well as testing and optimizing the compliment of adjustable settings. The project will be continued by Penn State's Engineers for a Sustainable World organization.

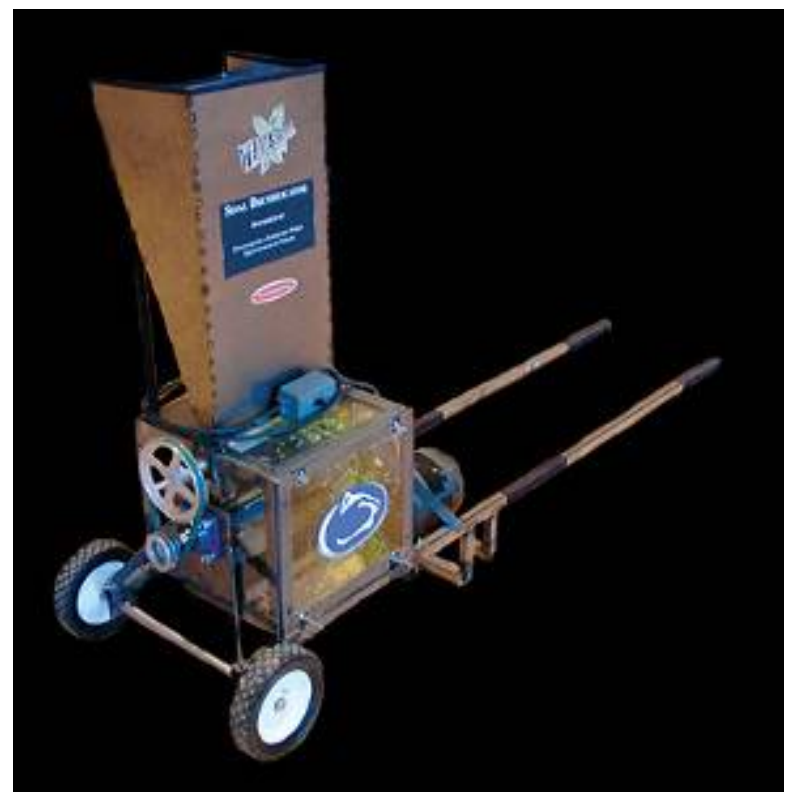

FIGURE 26

OPERATIONAL PROTOTYPE

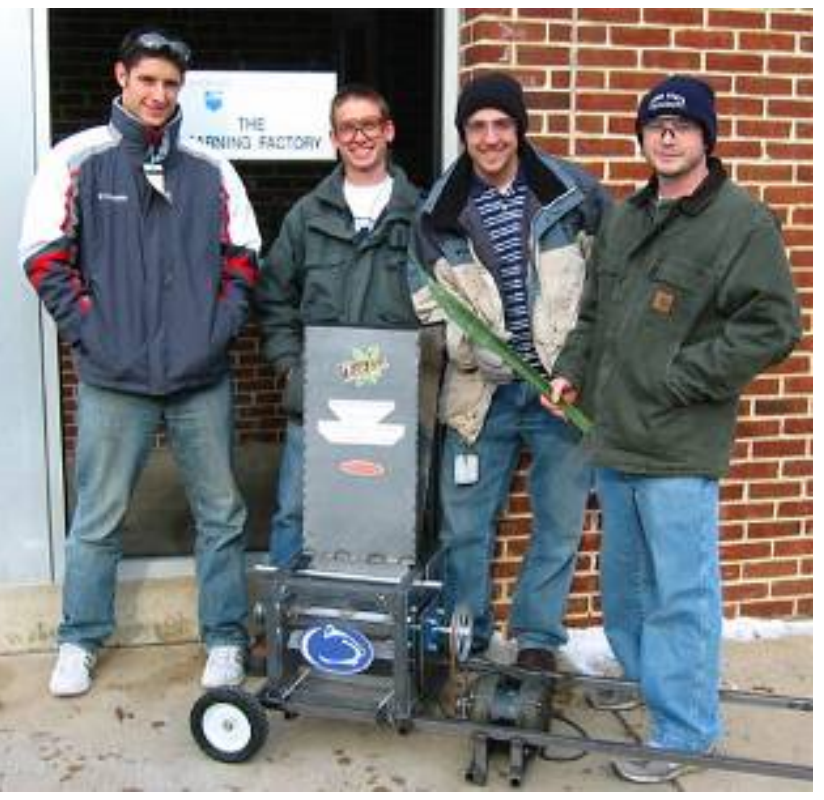

FIGURE 27

TEAM SISAL WITH PROTOTYPE

\section{ACKNOWLEDGMENT}

The authors would like to acknowledge assistance with this project from Dr. Moses Oduori, University of Nairobi; Desert Botanical Gardens, Phoenix, AZ; Carson Baird, Penn State University; Learning Factory supervisor, Learning Factory teaching assistant Allen Bussard; Dr. Leland Engel, Penn State University.

\footnotetext{
${ }^{1}$ Ikitoo, E. C., D. A. Mutuli and Fritz Kaestli (1998). Review of Past Research Results and Present Production Practices (Country Report for Kenya). Kenya Sisal Board.

${ }^{2}$ In Kiswahili, "ujamaa" can be interpreted to mean "kinship", but the word is used here in its political sense to mean "socialism".

${ }^{3}$ Oduri, Moses. Reasons Why Sisal Should Thrive in East Africa Again Department of Mechanical Engineering, University of Nairobi

${ }^{4}$ Kawongol, John B., Joseph K. Sentongo Kibalama, Larrry C. Brown. Design of a Decorticator for Small Scale Sisal Processing in Uganda. ASAE Annual Meeting. Chicago, Illinois, USA. July 28-July 31, 2002

${ }^{5}$ Oduori, Moses. Development of a Sisal Decorticator for Small Holder Producers and Traders. University of Nairobi.

${ }^{6}$ Email from Dr. Moses Oduori, University of Nairobi

${ }^{7}$ Email from Dr. Moses Oduori, University of Nairobi

${ }^{8}$ Email from Dr. Moses Oduori, University of Nairobi
} 


\section{APPENDIX}

Table 1: Component Screening Matrix (Cylinder/Blades)

\begin{tabular}{|l|l|l|l|l|}
\hline & Concept & Concept & Concept & Concept \\
\hline Selection Criteria & A & B & C & D \\
\hline & Reference & $\begin{array}{l}\text { Large } \\
\text { diameter w/ } \\
\text { rubber } \\
\text { blades }\end{array}$ & $\begin{array}{l}\text { Small } \\
\text { diameter } \\
\text { W/ rubber } \\
\text { blades }\end{array}$ & $\begin{array}{l}\text { Small } \\
\text { diameter } \\
\text { W/ metal } \\
\text { blades }\end{array}$ \\
\hline Manufacturability & 0 & 0 & + & + \\
\hline Durability & 0 & - & - & + \\
\hline Weight & 0 & 0 & + & + \\
\hline Safety & 0 & 0 & 0 & 0 \\
\hline Transportation & 0 & 0 & + & + \\
\hline Performance & 0 & 0 & 0 & 0 \\
\hline Ease of Use & 0 & 0 & 0 & 0 \\
\hline Cost & 0 & - & + & + \\
\hline & & & & \\
\hline Sum +'s & 0 & 0 & 4 & 5 \\
\hline Sum 0's & 8 & 6 & 3 & 3 \\
\hline Sum -'s & 0 & 2 & 1 & 0 \\
\hline & & & & \\
\hline Net Score & 0 & -2 & +3 & +5 \\
\hline Rank & 3 & 4 & Yes & Yes \\
\hline & & No & & \\
\hline Continue? & & & & 1 \\
\hline
\end{tabular}

Table 2: Component Scoring Matrix (Cylinder/Blades)

\begin{tabular}{|l|l|l|l|l|l|}
\hline & \multicolumn{3}{|l|}{} & Concept C & Concept D \\
\hline Selection Criteria & $\begin{array}{l}\text { Team } \\
\text { Weighting }\end{array}$ & Rating & $\begin{array}{l}\text { Weighted } \\
\text { Score }\end{array}$ & Rating & $\begin{array}{l}\text { Weighted } \\
\text { Score }\end{array}$ \\
\hline Manufacturability & $15 \%$ & 2 & .3 & 2 & .3 \\
\hline Durability & $10 \%$ & 1 & .1 & 3 & .3 \\
\hline Weight & $15 \%$ & 3 & .45 & 3 & .45 \\
\hline Safety & $5 \%$ & 2 & .1 & 2 & .1 \\
\hline Portability & $15 \%$ & 3 & .45 & 3 & .45 \\
\hline Performance & $15 \%$ & 2 & .3 & 2 & .3 \\
\hline Ease Of Use & $5 \%$ & 3 & .15 & 2 & .1 \\
\hline Cost & $20 \%$ & 2 & .4 & 3 & .6 \\
\hline & & & & & \\
\hline & Total Score & & 2.25 & & 2.60 \\
\hline & & & & & \\
\hline Continue & & & No & & Yes \\
\hline
\end{tabular}


Table 3: Component Screening Matrix (Motor Drive System)

\begin{tabular}{|l|l|l|l|l|}
\hline & Concept & Concept & Concept & Concept \\
\hline Selection Criteria & A & B & C & D \\
\hline & Reference & chain & gears & Direct \\
\hline Manufacturability & 0 & 0 & - & + \\
\hline Durability & 0 & + & + & - \\
\hline Weight & 0 & + & - & + \\
\hline Safety & 0 & 0 & 0 & 0 \\
\hline Transportation & 0 & 0 & 0 & 0 \\
\hline Performance & 0 & + & - & + \\
\hline Ease of Use & 0 & + & - & + \\
\hline Cost & 0 & - & - & + \\
\hline & & & & \\
\hline Sum +'s & 0 & 4 & 1 & 5 \\
\hline Sum 0's & 8 & 3 & 2 & 2 \\
\hline Sum -'s & 0 & 1 & 5 & 1 \\
\hline & & & & \\
\hline Net Score & 0 & 3 & -4 & 4 \\
\hline Rank & 3 & 2 & 4 & 1 \\
\hline & & & & \\
\hline Continue? & No & Yes & No & Yes \\
\hline
\end{tabular}

Table 4: Component Scoring Matrix (Motor Drive System)

\begin{tabular}{|l|l|l|l|l|l|}
\hline & \multicolumn{5}{|c|}{ Concept B } \\
\hline Selection Criteria & $\begin{array}{l}\text { Team } \\
\text { Weighting }\end{array}$ & Rating & $\begin{array}{l}\text { Weighted } \\
\text { Score }\end{array}$ & Rating & $\begin{array}{l}\text { Weighted } \\
\text { Score }\end{array}$ \\
\hline Manufacturability & $15 \%$ & 3 & .45 & 2 & .3 \\
\hline Durability & $10 \%$ & 3 & .3 & 1 & .1 \\
\hline Weight & $15 \%$ & 1 & .15 & 2 & .3 \\
\hline Safety & $5 \%$ & 2 & .1 & 3 & .15 \\
\hline Portability & $15 \%$ & 3 & .45 & 2 & .3 \\
\hline Performance & $15 \%$ & 3 & .45 & 2 & .3 \\
\hline Ease Of Use & $5 \%$ & 1 & .05 & 3 & .15 \\
\hline Cost & $20 \%$ & 2 & .4 & 3 & .6 \\
\hline & & & & & \\
\hline & Total Score & & 2.35 & & 2.2 \\
\hline & & & & & No \\
\hline Continue & & & Yes & & \\
\hline
\end{tabular}


Table 5: Component Screening Matrix (Feed Tray)

\begin{tabular}{|l|l|l|l|l|}
\hline & Concept & Concept & Concept & Concept \\
\hline Selection Criteria & A & B & C & D \\
\hline & Reference & $\begin{array}{l}\text { Spring } \\
\text { rollers }\end{array}$ & $\begin{array}{l}\text { Powered } \\
\text { rollers }\end{array}$ & $\begin{array}{l}\text { Vertical } \\
\text { feed }\end{array}$ \\
\hline Manufacturability & 0 & - & - & + \\
\hline Durability & 0 & 0 & 0 & 0 \\
\hline Weight & 0 & 0 & - & + \\
\hline Safety & 0 & 0 & + & + \\
\hline Transportation & 0 & 0 & 0 & + \\
\hline Performance & 0 & + & + & 0 \\
\hline Ease of Use & 0 & - & + & + \\
\hline Cost & 0 & - & - & + \\
\hline & & & & \\
\hline Sum +'s & 0 & 1 & 3 & 6 \\
\hline Sum 0's & 8 & 5 & 2 & 2 \\
\hline Sum -'s & 0 & 2 & 3 & 0 \\
\hline & & & & \\
\hline Net Score & 0 & -1 & 0 & +6 \\
\hline Rank & & & & \\
\hline & & & & \\
\hline Continue? & T-2 & 4 & T-2 & 1 \\
\hline
\end{tabular}

Table 6: Component Scoring Matrix (Feed Tray)

\begin{tabular}{|l|l|l|l|l|l|l|l|}
\hline & & \multicolumn{2}{l|}{ Concept A } & \multicolumn{2}{l|}{ Concept C } & \multicolumn{2}{l|}{ Concept D } \\
\hline Selection Criteria & $\begin{array}{l}\text { Team } \\
\text { Weighting }\end{array}$ & Rating & $\begin{array}{l}\text { Weighted } \\
\text { Score }\end{array}$ & Rating & $\begin{array}{l}\text { Weighted } \\
\text { Score }\end{array}$ & Rating & $\begin{array}{l}\text { Weighted } \\
\text { Score }\end{array}$ \\
\hline Manufacturability & $15 \%$ & 3 & .45 & 1 & .15 & 2 & .3 \\
\hline Durability & $10 \%$ & 3 & .3 & 2 & .2 & 3 & .3 \\
\hline Weight & $15 \%$ & 2 & .3 & 1 & .15 & 3 & .45 \\
\hline Safety & $5 \%$ & 2 & .1 & 2 & .1 & 3 & .15 \\
\hline Portability & $15 \%$ & 1 & .15 & 3 & .45 & 2 & .3 \\
\hline Performance & $15 \%$ & 2 & .3 & 3 & .45 & 2 & .3 \\
\hline Ease Of Use & $5 \%$ & 2 & .1 & 2 & .1 & 3 & .15 \\
\hline Cost & $20 \%$ & 2 & .4 & 1 & .2 & 3 & .6 \\
\hline & & & & & & & \\
\hline & $\begin{array}{l}\text { Total } \\
\text { Score }\end{array}$ & & 2.1 & & 1.8 & & 2.55 \\
\hline & & & & & & & \\
\hline Continue & & & No & & No & & Yes \\
\hline
\end{tabular}


Table 7: Component Screening Matrix (Safety Features)

\begin{tabular}{|l|l|l|l|l|}
\hline & Concept & Concept & Concept & Concept \\
\hline Selection Criteria & A & B & C & D \\
\hline & Reference & $\begin{array}{l}\text { Stick in } \\
\text { spokes }\end{array}$ & $\begin{array}{l}\text { Wound } \\
\text { spring }\end{array}$ & $\begin{array}{l}\text { Disk } \\
\text { break }\end{array}$ \\
\hline Manufacturability & 0 & + & + & - \\
\hline Durability & 0 & - & + & + \\
\hline Weight & 0 & + & + & - \\
\hline Safety & 0 & + & + & + \\
\hline Transportation & 0 & 0 & 0 & 0 \\
\hline Performance & 0 & + & + & + \\
\hline Ease of Use & 0 & 0 & 0 & 0 \\
\hline Cost & 0 & + & + & - \\
\hline & & & & \\
\hline Sum +'s & 0 & 5 & 6 & 3 \\
\hline Sum 0's & 8 & 2 & 2 & 2 \\
\hline Sum -'s & 0 & 1 & 0 & 3 \\
\hline & & & & \\
\hline Net Score & 0 & 4 & 6 & 0 \\
\hline Rank & T-3 & 2 & 1 & T-3 \\
\hline & & & & \\
\hline Continue? & & & & \\
\hline
\end{tabular}

Table 8: Component Scoring Matrix (Safety Features)

\begin{tabular}{|c|c|c|c|c|c|}
\hline (2) & & \multicolumn{2}{|c|}{ Concept B } & \multicolumn{2}{|c|}{ Concept C } \\
\hline Selection Criteria & $\begin{array}{l}\text { Team } \\
\text { Weighting }\end{array}$ & Rating & $\begin{array}{l}\text { Weighted } \\
\text { Score }\end{array}$ & Rating & $\begin{array}{l}\text { Weighted } \\
\text { Score }\end{array}$ \\
\hline Manufacturability & $15 \%$ & 1 & .15 & 1 & .15 \\
\hline Durability & $10 \%$ & 1 & .1 & 3 & .3 \\
\hline Weight & $15 \%$ & 3 & .45 & 3 & .45 \\
\hline Safety & $5 \%$ & 3 & .15 & 2 & .1 \\
\hline Portability & $15 \%$ & 3 & .45 & 3 & .45 \\
\hline Performance & $15 \%$ & 3 & .45 & 3 & .45 \\
\hline Ease Of Use & $5 \%$ & 1 & .05 & 3 & .15 \\
\hline Cost & $20 \%$ & 2 & .4 & 1 & .2 \\
\hline & Total Score & & 2.20 & & 2.25 \\
\hline Continue & & No & & Yes & \\
\hline
\end{tabular}


Table 9: Component Screening Matrix (Mobility Features)

\begin{tabular}{|l|l|l|l|l|}
\hline & Concept & Concept & Concept & Concept \\
\hline Selection Criteria & A & B & C & D \\
\hline & Reference & $\begin{array}{l}\text { Wheel } \\
\text { barrow }\end{array}$ & $\begin{array}{l}\text { Rick } \\
\text { shaw }\end{array}$ & Towable \\
\hline Manufacturability & 0 & - & - & - \\
\hline Durability & 0 & + & + & + \\
\hline Weight & 0 & 0 & 0 & 0 \\
\hline Safety & 0 & + & + & 0 \\
\hline Transportation & 0 & + & + & + \\
\hline Performance & 0 & + & + & + \\
\hline Ease of Use & 0 & + & + & - \\
\hline Cost & 0 & - & - & - \\
\hline & & & & \\
\hline Sum +'s & 0 & 5 & 5 & 3 \\
\hline Sum 0's & 8 & 1 & 1 & 2 \\
\hline Sum -'s & 0 & 2 & 2 & 3 \\
\hline & & & & \\
\hline Net Score & 0 & 3 & 3 & 0 \\
\hline Rank & T-3 & T-1 & T-1 & T-3 \\
\hline & & & & No \\
\hline Continue? & No & Yes & Yes & No \\
\hline
\end{tabular}

Table 10: Component Scoring Matrix (Mobility Features)

\begin{tabular}{|c|c|c|c|c|c|}
\hline & & \multicolumn{2}{|c|}{ Concept B } & \multicolumn{2}{|c|}{ Concept C } \\
\hline Selection Criteria & $\begin{array}{l}\text { Team } \\
\text { Weighting }\end{array}$ & Rating & $\begin{array}{l}\text { Weighted } \\
\text { Score }\end{array}$ & Rating & $\begin{array}{l}\text { Weighted } \\
\text { Score }\end{array}$ \\
\hline Manufacturability & $15 \%$ & 2 & .3 & 2 & .3 \\
\hline Durability & $10 \%$ & 2 & .2 & 3 & .3 \\
\hline Weight & $15 \%$ & 2 & .3 & 1 & .15 \\
\hline Safety & $5 \%$ & 1 & .05 & 3 & .15 \\
\hline Portability & $15 \%$ & 3 & .45 & 3 & .45 \\
\hline Performance & $15 \%$ & 2 & .3 & 3 & .45 \\
\hline Ease Of Use & $5 \%$ & 1 & .05 & 3 & .15 \\
\hline Cost & $20 \%$ & 2 & .4 & 1 & .2 \\
\hline & Total Score & & 2.05 & & 2.15 \\
\hline Continue & & & No & & Yes \\
\hline
\end{tabular}


Table 11: Component Screening Matrix (Casing)

\begin{tabular}{|l|l|l|l|l|}
\hline & Concept & Concept & Concept & Concept \\
\hline Selection Criteria & A & B & C & D \\
\hline & Reference & Plastic box & $\begin{array}{l}\text { Sheet } \\
\text { metal box }\end{array}$ & $\begin{array}{l}\text { Rounded } \\
\text { metal }\end{array}$ \\
\hline Manufacturability & 0 & + & + & - \\
\hline Durability & 0 & - & - & - \\
\hline Weight & 0 & + & + & + \\
\hline Safety & 0 & - & 0 & 0 \\
\hline Transportation & 0 & 0 & 0 & 0 \\
\hline Performance & 0 & - & - & 0 \\
\hline Ease of Use & 0 & + & + & 0 \\
\hline Cost & 0 & + & + & + \\
\hline & & & & \\
\hline Sum +'s & 0 & 4 & 4 & 3 \\
\hline Sum 0's & 8 & 0 & 2 & 4 \\
\hline Sum -'s & 0 & 3 & 2 & 1 \\
\hline & & & & \\
\hline Net Score & 0 & 1 & 2 & 1 \\
\hline Rank & 4 & 2 & 1 & 2 \\
\hline & & & & \\
\hline Continue? & & & & \\
\hline
\end{tabular}

Table 12: Component Scoring Matrix (Casing)

\begin{tabular}{|c|c|c|c|c|c|}
\hline & & \multicolumn{2}{|c|}{ Concept B } & \multicolumn{2}{|c|}{ Concept C } \\
\hline Selection Criteria & $\begin{array}{l}\text { Team } \\
\text { Weighting }\end{array}$ & Rating & $\begin{array}{l}\text { Weighted } \\
\text { Score }\end{array}$ & Rating & $\begin{array}{l}\text { Weighted } \\
\text { Score }\end{array}$ \\
\hline Manufacturability & $15 \%$ & 2 & .3 & 3 & .45 \\
\hline Durability & $10 \%$ & 2 & .2 & 3 & .3 \\
\hline Weight & $15 \%$ & 3 & .45 & 1 & .15 \\
\hline Safety & $5 \%$ & 2 & .1 & 3 & .15 \\
\hline Portability & $15 \%$ & 3 & .15 & 2 & .3 \\
\hline Performance & $15 \%$ & 2 & .3 & 2 & .3 \\
\hline Ease Of Use & $5 \%$ & 3 & .15 & 3 & .15 \\
\hline Cost & $20 \%$ & 3 & .6 & 2 & .4 \\
\hline & Total Score & & 2.25 & & 2.20 \\
\hline Continue & & & Yes & & No \\
\hline
\end{tabular}


Table 13: Variables and units for Pitch calculation

\begin{tabular}{|l|l|l|}
\hline Variable & Meaning & Units \\
\hline $\mathrm{p}$ & Pitch & in \\
$\mathrm{v}$ & $\begin{array}{l}\text { Linear Feed } \\
\text { Rate }\end{array}$ & $\mathrm{in} / \mathrm{s}$ \\
\hline $\mathrm{\omega}$ & $\begin{array}{l}\text { Rotational } \\
\text { Velocity }\end{array}$ & $\mathrm{rad} / \mathrm{s}$ \\
\hline $\mathrm{n}$ & $\begin{array}{l}\text { Number of } \\
\text { blades }\end{array}$ & Unitless \\
\hline
\end{tabular}

